\title{
Parental Demographic Variables as Determinants of Knowledge of Nutritional Needs of Preschoolers in North Central Zone, Nigeria
}

\author{
Wilfred Iorfa Achagh ${ }^{1}$, Victor S. Ezema ${ }^{2}$, Bukola Bisola Ogundele ${ }^{3}$, Comfort Bissallah Ekele ${ }^{4}$, \\ Afusat Ejide Badamasi ${ }^{5}$, Helen Arinola Ashefor ${ }^{1}$, Alexander Chuwkuemeka Okondugba ${ }^{2}$, \\ Emmanuel Chidobe Okenyi ${ }^{2}$, Julie U. Ibiam ${ }^{2}$, Florence Eleje Otta ${ }^{6}$, Clara O. Ifelunni ${ }^{2}$, Gloria C. Ugwu ${ }^{2}$, \\ Joy Chioma Orji \& Christian S. Ugwuanyi ${ }^{8}$ \\ ${ }^{1}$ Department of Early Childhood Care and Education, FCT College of Education Zuba, Abuja, Nigeria \\ ${ }^{2}$ Department of Educational Foundations, University of Nigeria, Nsukka, Nigeria \\ ${ }^{3}$ Department of Educational Foundations, FCT College of Education Zuba, Abuja, Nigeria \\ ${ }^{4}$ Department of Primary Education, FCT College of Education Zuba, Abuja, Nigeria \\ ${ }^{5}$ Department of Educational Psychology, FCT College of Education Zuba, Abuja, Nigeria \\ ${ }^{6}$ Department of Educational Foundations, Ebonyi State University, Abakaliki, Nigeria \\ ${ }^{7}$ Institute of Education, University of Abuja, Nigeria \\ ${ }^{8}$ Postdoctoral fellow, School of Education Studies, Faculty of Education, University of the Free State, \\ Bloemfontein, South Africa. \\ Correspondence: Christian S. Ugwuanyi, Postdoctoral fellow, School of Education Studies, Faculty of Education, \\ University of the Free State, Bloemfontein, 9300, South Africa. E-mail: ugwuanyics@ufs.ac.za
}

Received: December 20, 2019 Accepted: February 25, 2020 Online Published: March 11, 2020

doi:10.5539/gjhs.v12n5p10

URL: https://doi.org/10.5539/gjhs.v12n5p10

\begin{abstract}
The general purpose of the study was to determine the influence of demographic variables of parents on knowledge and practices of nutritional needs and cognitive readiness of preschoolers in North Central Zone, Nigeria. The study adopted an ex post facto research design with a sample of 400 parents of preschool children drawn using multistage sampling procedure. Two instruments were used for data collection; "Parental Knowledge and Practices of Nutritional Needs of Preschoolers Questionnaire (PKPNNPQ) and Parental Knowledge and Practices of Cognitive Readiness of Preschoolers Questionnaire (PKPCRPQ). The instruments were validated by three experts. The reliability indices of the instruments were estimated using Cronbach's Alpha approach. The overall reliability coefficients of PKPNNPQ and PKPCRPQ were 0.84 and 0.82 respectively. Data collected were analyzed using mean, ANOVA and t-test statistics. Mean was used to answer all the research questions, while ANOVA and t-test statistics were used to test all the null hypotheses at 0.05 level of significance. Findings revealed that parents' occupation had significant influence on their knowledge, and practice of the nutritional needs of preschoolers while location had no significant influence. It was therefore recommended that parents in different occupations should be educated and equipped with the necessary knowledge in their workplace about the nutritional needs of preschoolers.
\end{abstract}

Keywords: children, demographic variables, nutritional needs, parents

\section{Introduction}

The world over, countries that invest in children in terms of quality education, security, quality child care services, diseases control and adequate nutrition are the ones driving the course of development today. Apart from the interest and the investment of government, families have equally played a crucial role in the upbringing and survival of the children. The concept of child is viewed differently, but generally a child is a person under the age of eighteen years. Melton (2005) sees a child as anybody who is 12 years or below. According to the United Nation Scientific and Cultural Organization ([UNESCO], 2016), a child is a human being between the stages of birth and puberty. In the context of this study however, a child is defined as a young person who has not attained maturity.

In the process of growing up children pass through different stages of development to attain full maturity. According to Barnett and Belfield (2006) the stages of child development include: neonates (ages 0-1 month); 
infant (ages 1 month - 1 year); toddler (ages 1-3 years); preschooler (ages 3-5years); primary school (ages 6-13 years). At each stage of development the child requires certain amount of care and protection to realize his or her full potentials. The developmental process of a child is influenced by genetic or environmental factors. Specifically, nurture or environment has been identified to have a critical role to play in a child's development after birth. According to Ngwoke and Eze (2010), nurture describes anything within the environment (like nutrition) that may influence the course of human development. By virtue of birth, a child finds his or herself in a close-knit family unit which determines the child's nutritional patterns. At different stages of development, children have peculiar needs particularly around 3-5 five years which is the preschool stage, this needs if well met promotes their all-round development.

A preschool is a learning environment that caters for children of ages 3 to 5 years. A preschooler is any child who has not reached the age of primary school. In this study, preschool is a school that caters for the learning needs of children of about the age of 3-5 years before they are enrolled into primary school. The concept of preschool is also known as early childhood care and education or pre-primary education. Preschoolers are unique persons; they are happy, friendly, hilarious and always curious about life (Okondugba, 2015). Preschoolers have certain characteristics namely: intellectual, social, emotional, physical and spiritual. Intellectually, preschoolers are explorative, they like to discover things in their immediate environment. They perceive object as it is and observe them keenly to notice its dimensions and taste. Socially preschoolers like to love and be loved in return. They like to interact with people in their environment who play one significant role or the other in their lives. Emotionally preschoolers are very sensitive to pleasure and pain. Everything which elicits pleasure attracts their attention like the noise of rattling object or the sound of music. When they are uncomfortable they cry for help to be relieved of their discomfort. Physically, preschoolers have a lot of energy to burn, they like to engage in play activities both at home and in school. Spiritually, preschoolers have a growing sense that God is very special and real rather than pretend, tend to have a very literal concept of God, perhaps as a "grandfather" figure who lives "up there" they also readily accept what you say about God.

The Federal Republic of Nigeria (FRN, 2014) document the National Policy on Education Split preschool into early child care development and education, and pre-primary school. Early child care development as contained in the document is a learning environment that provides care and protection, stimulation for children from age $0-4$ years in a crèche or nursery. The document also defined pre-primary education as a one-year education given to children age 5 before their entering primary school. According to the Federal Government of Nigeria document (FRN, 2014) preschool covers the last year in crèche or nursery to one year pre-primary school (3-5years). At this level of life, provision of care, food, good health habits and security is a shared responsibility of parents and school but specifically, the parents make provision for the majority of the child's needs including nutrition. The preschool stage is delicate and crucial, it is at this stage the child's brain reaches $80 \%$ of its development therefore proper care and adequate nutrition is required to enhance their growth and development.

Nutrition is a critical aspect of child development. World Health Organization (WHO, 2009) defined nutrition as the intake of food considered in relation to the body's dietary needs. Good nutrition is a cornerstone for good health. The constituents of these foods are called nutrients. There are two main types of nutrients, macronutrients and micronutrients. The three main categories of macronutrients include carbohydrate, protein, and fat. The two types of micronutrients are vitamins and minerals. Food supplies essential nutrients that the body requires for energy, growth and development, resistance to illness, infection and tissue repair. In the context of this study, nutrition is defined as all the processes used by the child to take in and to digest, absorb, transport, utilize and excrete food substances. Children growth and development can effectively be enhanced by their food intake and nutritional needs. Nutritional needs are all the food in adequate proportion needed by the child for proper growth and development. The nutritional needs and food requirements for preschoolers (3-5 years) vary for different nutrients in relation to their role in growth of specific tissue (Srilakshmi, 2011). The nutritional requirements of children are energy food, protein, carbohydrate, fats and oil, vitamins, minerals and water. Energy food is required for growth and activity. Insufficient food will not only result in undernutrition in terms of inadequate weight gain but will also hinder growth. According to Ngwu (2012), the increase in the muscle mass that must accompany bone growth requires positive nitrogen balance that is met by a protein intake of 1.5 to $2 \mathrm{~g} / \mathrm{kg}$. Bodyweight fat according to $\mathrm{Ngwu}$, is also needed by the preschoolers. Minerals are also essentially needed by children and an example of such minerals is calcium which helps in the strengthening of the bones. Others nutrients like vitamins are essentially needed for the growth of tissues and repairs.

However, when these nutritional needs are not properly met it could lead to protein-energy deficiency diseases or malnutrition which may consequently affect the child's performance in school. In the view of this Atkins (2002) maintained that malnutrition remains one of the major contributing factors to disease and death in the world, while 
its impact is greatest in poor and underdeveloped parts of the world, where diseases associated malnutrition accounts for $49 \%$ of deaths in children under the age of 5 years. Lack of access at all times to a sufficient quantity and quality of safe and nutritious food for an active and healthy life can cause under-nutrition and micronutrient deficiencies which consequently affect children development (Food and Agricultural Organization (FAO) and United Nations Development Programme (UNDP, 2001).

The role good nutrition plays at the early stage of a child's life cannot be overemphasized. Okolie (2005) observed that most children in Nigeria fall sick as a result of being malnourished for a long period. This situation, most often, leads to a prolonged deficiency of appropriate vitamins, minerals and proteins which could cause some serious health and learning difficulties. In the same line of thought, Strauss and Thomas (2008) presented literature suggesting that health in early life may have substantial effects on health and well-being throughout the entire life. As such, diet and exercise patterns modelled by parents or adopted during these developmental years is key for lifelong habits that can promote proper development in later years.

A parent is a caretaker of offspring of their own species. Parents shape the child through interaction in the family (Okondugba, 2015). A parent could be a biological or surrogate parent. A biological parent is a person whose gamete resulted in the production of the child. However, some parents may not be biologically related to the child; they are those surrogate parents who nurture and raise the offsprings of other parents who are not biologically related to them. Hence, parents are seen generally to as caregivers or caretakers.

Parents can either make or mar their children's future by the role they play in the child's life. According to Lifecho (2012), the first role of the parents is taking care of the child's biological needs. This includes providing physical care to fulfil the needs of the child such as good food, fresh air, good lighting, enough sleep, recreation time and so on. Parents also provide an optimal environment for children, protection, education, guidance, direction, assistance and help, support and motivation among others. To further support this, Ngwu (2012) asserts that the convention on the child rights has established social and economic rights, right to survival, early development, education, health care and good nutrition for the child. This is because whatever role parents play at the foundational stage will be the patterns which the child will emulate throughout life. As a result, parents need adequate knowledge of children's nutritional needs to promote children's learning, good health and cognitive readiness.

Knowledge in the view of Ogomaka (2005) may technically imply the lowest category in the taxonomy of the cognitive domain/learning outcomes comprising human capabilities as recalling facts and definitions, identifying/ recognizing objects or labelling such objects and computing. Knowledge comprised of what an individual has made sensory impressions of and also implies the entire experience gained through learning. Knowledge according to Awopetu, and Salamatu (2019) refers to facts, information and skills gained through experience or education and understanding of an issue or phenomenon. In this study knowledge is the factual information on the developmental needs of children that parents possess for children's nutritional needs.

Parents need to acquire a sound knowledge of how to bring up children. In the opinion of Winter, Morawska and Sanders (2012), parenting is multidimensional and to respond to the varied needs of the children, parents must develop both depth and breadth of knowledge ranging from being aware of developmental milestones and norms that help in keeping children safe and healthy to understand the role of professionals that interact with families. Parents knowledge of how to meet children's basic needs like physical (e.g. food) and emotional needs as well as how to read children's cues and signals, can improve the synchronicity between parents and children ensuring proper child growth and development. Also, parents' knowledge about proper nutrition, safe sleep environment, how to soothe a crying baby, how to show love and affection is critical for young children development (Chung-park, 2012). Parents' Knowledge could be influenced by demographic characteristics.

Demography is the study of the population statistics in relation to certain human variables. According to Schiffman and Leslie (2004), demography is the study of the vital and measurable statistics of a population. Demographic variables include age, gender, marital status, family size, family life cycle, income, occupation, education, religion, race, generation, nationality and social class (Kotler, 2003). Demographic determinants also refer to socioeconomic characteristics of a population such as age, sex, education level, income level, marital status, occupation, religion, birth rate, death rate, the average size of a family, the average age at marriage (Kumar, 2013). Demographics are used to describe a population in terms of size, distribution and structure. Size means the number of individuals in a population while structure describes the population in terms of age, income, education and occupation. Distribution of the population describes the location of individuals in terms of geographic regions and rural, urban or suburban locations. Kumar further stated that each of these variables may influence parents' knowledge, practices of nutritional needs and cognitive readiness of children.

In the view of the above, this study considered parental demographic variables such as parents' occupation and 
location, the extent to which they influence parents' knowledge of nutritional needs of preschoolers was examined. The reason for the choice of these demographic variables considered was that in the North Central, majority of the people share similar demographic characteristics like religion, culture, tribe and so on. But there was a perceived gap in occupation and location and these variables seemed to influence parents' knowledge and of children nutritional needs. Occupation is defined by the International Labour Organization (ILO, 2008) as a set of jobs whose main tasks and duties are characterized by a high degree of similarity. Parents' occupation in this study refers to the type of work the father and mother engage in. This is categorized into three groups: (1) Business: this category includes those who are skilled and self-employed (2) Formal: this category includes those who are skilled and work in public or private organizations. They include professionals as well as those in service-oriented professions but exclude those in manual occupations. (3) Artisan: this category includes those in unskilled and semi-skilled and manual occupations. Parents' occupation may predict the level of family income and standard of living generally. Ejieh (2009) agrees that children from poor home background often suffer serious diseases due to malnutrition and poor standard of living that leads to poor performance at school. Certain occupations influence people's choice of location.

A location is a place or position where people, objects or animals live or are kept. It could be seen as a place where an activity takes place. Location, according to Unamma (2003) is a place or places where things, buildings, schools, market, among others are situated. Also, Adesanya (2012) view location as a place where events happen. Contextually, location refers to all places where structures and people are found which may be a rural or urban area Location is a critical demographic factor. It may determine the knowledge and behaviour of individuals as Abolarin (2014), stated that parents in rural areas behave differently from those in the urban areas. The urban areas are densely populated with a lot of infrastructural and instructional facilities while the rural areas have a low population with a near dearth of infrastructure and expert knowledge on health and nutritional needs. The urban citizens may be more educated than rural communities. Research has shown the dichotomy between urban and rural areas in North Central Zone, Nigeria as the zone is made of urban and rural areas and each of these locations with people of different demographic characteristic

Given the influence of these demographic characteristics and other factors on parents, the federal government of Nigeria introduced school feeding in public preschools and primary schools across the country as an intervention to encourage education for all. However, this wonderful intervention seen to be limited as only a few schools in each Local Government Area were used as demonstration schools to try out the effectiveness of the programme while numerous public and private schools are not included in the intervention programme yet. Few private preschools also practice school feeding but the number is scanty. As a result majority of parents in North central Nigeria from varying occupation and location though, sometimes with children from same schools, give children food from home to take to school, these foods are prepared differently. They may or may not contain adequate diets and this could be as a result of variation in parents' knowledge about adequate diet or parents' location or occupation. Some children also come to school without eating at home, bringing food to school or money to buy food in school either. Those that bring food to school are not allowed to eat until break time, which sometimes before the break time the food gets cold. The quality of the food and the combination of the right proportion of essential food nutrients preschoolers take to school to a large extent could be a reflection of the parents' knowledge about nutritional needs of the children. Sometimes children return home very hungry with food from school that is not well prepared. When children stay in school hungry it could affect their attention in class, brain development, health and cognitive readiness.

The researcher also observed that some foods children take to school contain too much sugar, fatty or over-concentration of one nutrient or the other. Also, some parents give children the same type of diets throughout the week, such feeding pattern may contribute to obesity and tiredness in class. The poor state or nature of school feeding in the North Central Nigeria preschools was what prompted the need for the study.

\subsection{Research Questions}

The following research questions were posed for the study;

1) What is the influence of parents' occupation on their knowledge of the nutritional needs of preschoolers?

2) What is the influence of parents' location on their knowledge of the nutritional needs of preschoolers?

\subsection{Hypotheses}

The following hypotheses were formulated to guide the study and were tested at a 0.05 level of significance. 


\section{Materials and Methods}

This study adopted ex post facto research design. Ex post facto design seeks to establish a cause-effect relationship between variables but the researcher have no control over the variables of interest and therefore cannot manipulate them Nworgu (2015). This design was adopted because the researcher worked with variables that already existed before the research. The study was carried out among parents in North central, Nigeria. The North central is made up of the Federal Capital Territory (FCT) Abuja, and the following six states: Benue, Kogi, Kwara, Nasarawa, Niger, and Plateau states. The North Central Geo-Political Zone is also referred to as the middle belt of Nigeria. The economic activities in the North Central, Nigeria are activities like cattle herding, agriculture, commerce, cement, palm oil production, Tin, natural gas, semi-precious stones, rich in coal and ceramics. The economic activities in the region make parents belong to different occupations, acquire different qualifications and also find themselves in different locations. In the region, cost of living, schooling and educational standards, as well as income levels of the parents vary (National Population Commission, 2016). These variations could, in turn, create discrepancies on the knowledge and practices of parents on the nutritional needs of their children.

The population of the study comprised 858,600 parents who are members of the parent-teachers association (PTA) in both public and private preschools in North central, Nigeria. The sample for the study was 400 parents of preschool children. Multiple stage sampling procedure was used in drawing the sample. At the first stage, a simple random sampling technique was used to draw three states; Benue, Nasarawa states and Abuja. Specifically, the slip of paper method was used. Secondly, proportionate stratified sampling technique was used. The sample fraction is: $\mathrm{n} / \mathrm{N}=400 / 412300=.00097017$. This fraction was used to determine the size of each stratum (state) to be drawn for the sample. In the third stage, purposive sampling was used to draw 18 local government areas (Abuja=6 L.G.A.: Nasarawa $=6$ L.G.A. and Benue $=6$ L.G.A.).

Two instruments were used for data collection of this study. The instruments are "Parental Knowledge and Practices of Nutritional Needs of Preschoolers Questionnaire (PKPNNPQ)" and "Parental Knowledge and Practices of Cognitive Readiness of Preschoolers Questionnaire (PKPCRPQ)". The instrument (PKPNNPQ) consisted of two sections. Section 'A' elicited information on respondents' demographic variables. The variable includes Parents' occupation, level of education and location (Urban or Rural). Section 'B' consisted of 20 items. Cluster A elicit information on knowledge of nutritional needs of preschoolers and contained 10 items and cluster $\mathrm{B}$ elicited information on practices of nutritional needs of preschoolers. Also, the questionnaire (PKPCRPQ) consisted of two sections. Section 'A' elicited information on respondents' demographic variables. The variable includes Parents' occupation, level of education and location (Urban or Rural). Section 'B' consisted of 22 items. Cluster A was made up of 10 items and elicited information on cognitive readiness of preschoolers while cluster $B$ contained 12 items and elicited information on practices of cognitive readiness. The instruments in a Likert-type questionnaire format graded on a four-point scale of strongly agree (SA), agree (A), disagree (D) and strongly disagree (SD) with numerical values of 4, 3, 2 and 1.

The instruments were face validated by three experts: two in Childhood Education unit, one in and one expert in Measurement and Evaluation Unit, all in Faculty of Education, University of Nigeria, Nsukka (UNN). The experts were requested to go through the instruments and ascertain their appropriateness for the study bearing in mind the purposes of the study, research questions and hypotheses. The experts were also requested to check the appropriateness of the language and the instructions given to the respondents. Three copies of the validated instruments were retrieved from the experts. Thus, based on their comments and suggestions, corrections were made to improve the quality of the instruments.

The instruments were trial-tested was on a sample of 30 parents of preschoolers in Kaduna state, which is outside the area of the study but has the same characteristics with the area of study. The data obtained were subjected to reliability estimate to determine the internal consistency reliability indices of the items of the instrument using Cronbach's Alpha method since the items were polytomously scored. The reliability coefficients of 0.85 and 0.81 were obtained for clusters A and B of PKPNNPQ respectively whereas, 0.78 and 0.82 were obtained for clusters A and B of PKPCRPQ respectively. The overall reliability coefficients of PKPNNPQ and PKPCRPQ were 0.84 and 0.82 respectively.

The researcher and six research assistants, who were briefed by the researchers in the administration of the questionnaire, administered the copies of the questionnaire to the respondents. The administration and retrieval of the questionnaire were done at PTA meetings and it lasted for a period of three weeks. Mean and standard deviation was used to answer all the research questions. Items with a mean of 2.50 and above were accepted while items with less were rejected. Hypotheses 1, 2, 7, and 8 were tested using ANOVA and post-hoc analysis was also used to determine the direction whenever the ANOVA result shows significant difference whereas hypotheses 3, 4, 5, 6, 9, 
10,11 and 12 were tested using t-test. All the hypotheses were tested at a 0.05 level of significance. In the decision rule, the researcher rejected any null hypothesis that the associated probability (sig) value is less than 0.05 level of significance set as benchmark and failed to reject any null hypothesis that the associated probability (sig) value is greater than 0.05

\section{Results}

\subsection{Research Question One}

What is the influence of parents' occupation on their knowledge of the nutritional needs of preschoolers?

Table 1. Mean and Standard Deviations of the influence of parents' occupation on their knowledge of the nutritional needs of preschoolers

\begin{tabular}{|c|c|c|c|}
\hline Parents' Occupation & $\mathbf{N}$ & & SD. \\
\hline Professional & 176 & 3.13 & 0.49 \\
\hline Business & 128 & 2.89 & 0.48 \\
\hline Artisan & 96 & 2.16 & 0.51 \\
\hline
\end{tabular}

Key: $\overline{\boldsymbol{X}}=$ Mean, $\mathrm{SD}=$ Standard Deviation .

Result in Table 1 shows the mean responses and standard deviations of respondents with respect to the influence of parents' occupation on their knowledge of the nutritional needs of preschoolers. The result shows that Professionals had a mean response of $(x=3.13, \mathrm{SD}=0.49)$, Business $(x=2.89, \mathrm{SD}=0.48)$ and Artisans had a mean of $(\bar{x}=2.16, \mathrm{SD}=0.51)$. This result indicates that parents who are Professionals have the highest knowledge of the nutritional needs of preschoolers followed by those who are in business and the least being those who are Artisans. Based on the observed differences in mean scores of the three groups, it could be deduced that parents' occupation may influence parents' knowledge of the nutritional needs of preschoolers.

$\mathbf{H O}_{1}$ : There is no significant influence of parents' occupation on their knowledge of the nutritional needs of preschoolers.

Table 2. ANOVA analysis of the influence of parents' occupation on their knowledge of the nutritional needs of preschoolers

\begin{tabular}{lllllll}
\hline & Sum of Squares & df & Mean Square & F & Sig. & Dec. \\
\hline Between Groups & 58.752 & 2 & 29.376 & 118.202 & 0.00 & $\mathrm{~S}$ \\
Within Groups & 98.663 & 397 & .249 & & & \\
Total & 157.415 & 399 & & & \\
\hline
\end{tabular}

Key: $\mathrm{df}=$ degree of freedom, $\mathrm{F}=$ ANOVA test statistic, Sig. $=$ Significant level/Exact probability value, Dec. $=$ Decision, $\mathrm{S}=$ Significant.

Result in Table 2 shows that there was a significant influence of parents' occupation on their knowledge of the nutritional needs of preschoolers, $F(2,397)=118.202, p=0.000$. Since the associated probability value of 0.00 is less than the 0.05 level of significance, the null hypothesis was therefore rejected. In order to determine the direction of the influence among the three groups, the Scheffe Post-Hoc test was further conducted and the result presented in Table 3. 
Table 3.Scheffe Post-Hoc test of the influence of parents' occupation on their Knowledge of the nutritional needs of preschoolers

\begin{tabular}{llllll}
\hline (I) Occupation & (J) Occupation & Mean Difference (I-J) & Std. Error & Sig. & Dec. \\
\hline Professional & Business & $.23629^{*}$ & .05791 & .000 & $\mathrm{~S}$ \\
& Artisan & $.96468^{*}$ & .06325 & .000 & $\mathrm{~S}$ \\
\multirow{2}{*}{ Business } & Professional & $-.23629^{*}$ & .05791 & .000 & $\mathrm{~S}$ \\
& Artisan & $.72839^{*}$ & .06731 & .000 & $\mathrm{~S}$ \\
\multirow{2}{*}{ Artisan } & Professional & $-.96468^{*}$ & .06325 & .000 & $\mathrm{~S}$ \\
& Business & $-.72839^{*}$ & .06731 & .000 & $\mathrm{~S}$ \\
\hline
\end{tabular}

*. The mean difference is significant at the 0.05 level.

Result in Table 3 shows a Post-Hoc test result for the influence of parents' occupation on their Knowledge of the nutritional needs of preschoolers. The result showed that mean difference $(\alpha<0.05)$ between Professional and Artisans had the highest positive mean difference among others and thus contributed most to the significant influence of occupation on nutritional needs of preschoolers.

\subsection{Research Question Two}

What is the influence parents' location on knowledge of the nutritional needs of preschoolers?

Table 4. Mean and Standard Deviations of the influence parents' location on knowledge of the nutritional needs of preschoolers $(\mathrm{N}=400)$

\begin{tabular}{llll}
\hline Location & $\mathbf{N}$ & Mean & Std. Deviation \\
\hline Urban & 276 & 2.85 & 0.63 \\
Rural & 124 & 2.75 & 0.61 \\
\hline
\end{tabular}

The result shows that respondents from urban location had a mean response of $(\bar{x}=2.85, \mathrm{SD}=0.63)$ while their rural counterparts had a mean of $(\bar{x}=2.75, \mathrm{SD}=0.61)$. The mean response for urban respondents is slightly higher than that of their rural counterparts. This, therefore, implies that parents' location may influence their knowledge of the nutritional needs of preschoolers in favour of those from urban.

$\mathbf{H O}_{2}$ : There is no significant influence of parents' location on their knowledge of the nutritional needs of preschoolers.

Table 5. t-test analysis of the influence of parents' location on their knowledge of the nutritional needs of preschoolers

\begin{tabular}{llllllll}
\hline Location & $\mathbf{N}$ & Mean & Std. Deviation & t-val & df & Sig. & Dec \\
\hline Urban & 276 & 2.85 & 0.63 & 1.419 & 398 & 0.15 & NS \\
Rural & 124 & 2.75 & 0.61 & & & &
\end{tabular}

Key: $\mathrm{t}$-val $=\mathrm{t}$-test value, $\mathrm{df}=$ degree of freedom, Sig. $=$ Significant level/Exact probability value, Dec. $=$ Decision, NS $=$ Not significant.

The result in Table 5 shows there is no significant influence of parents' location on their knowledge of the nutritional needs of preschoolers, $t(398)=1.419, p=0.15$. Since the probability value of 0.15 was greater than the 0.05 set as the level of significance for testing the hypothesis, the researcher failed to reject the null hypothesis. 


\section{Discussion of the Findings}

The findings of the study showed that most parents have knowledge of the nutritional needs of preschoolers. This implies that many parents are aware of the various nutritional needs of preschoolers. The increasing rate of education in the country could be the reason parents are now enlightened about the nutritional needs of their children or preschoolers. In essence, if parents are well informed about the nutritional needs of preschoolers, they will be more knowledgeable and equipped to meet the nutritional needs of preschoolers.

This finding agreed with that of Sönmez, Kolaşınlı, Topcan, and Paylaş (2017) who reported that parents have information about the advantages of different food groups, including digestion, growth and intelligence. However, the finding disagrees with that of $\mathrm{Ngwu}$ (2012) who examined the knowledge of infant nutritional needs and reported that many Nigerian families are not aware that they can mash carrot, potato and cucumber and mix with meat broth to feed their children. Also, the finding disagreed with that of Ngwu, Ezeh and Iyiani (2014) who examined the knowledge of infant nutrition in Enugu State, Nigeria and revealed that parents had low knowledge of infant nutrition.

The finding of the study also showed that parents' occupation influences their knowledge of the nutritional needs of preschoolers. This implies that the parents' occupation plays an important role in their knowledge of preschoolers' nutritional needs. This finding is in line with the finding of Ijarotimi and Ijadunola (2007) who stated that occupations of parents such as civil service, petty business, farming and vocational jobs contribute to the nutritional status of their children. Similarly, the finding corroborates that of Onubogu, Edokwe and Okeke (2014) who stated that parents' occupation was significantly associated with lunch pack contents. These findings show that parents' occupation such as professional, business or artisans determine their knowledge of the nutritional needs of preschoolers. In essence, what parents as professionals know about the nutritional needs of preschoolers may vary from that of business parents as well as those who are artisans. Thus, there was a significant influence of parents' occupation on their knowledge of the nutritional needs of preschoolers

The findings further revealed that parents' location has a slight influence on their knowledge of the nutritional needs of preschoolers in favour of those from Urban. This means that parents in urban areas slightly know the nutritional needs of preschoolers than their counterparts in rural areas. This could be so because parents in urban areas may be more enlightened than those in rural areas. The finding agreed with the finding of Agbon (2007) who stated that the diet of preschool children in the rural areas was a monotonous one containing mainly roots, cereals, beans and tuber while dishes with negligible quantities of fish and meat and fruits were taken occasionally. However, the finding is contrary to the finding by Ngwu (2012) who reported that the place of residence had no relationship with any of the dependent variables like knowledge of children's nutrition. This suggests that there could be no significant influence of location on parents' knowledge of the nutritional needs of preschoolers.

\section{Conclusion and Recommendations}

It was also concluded that parents' occupation has a significant influence on their knowledge of the nutritional needs of preschoolers. Furthermore, the study concluded that parents' location has a slight significant influence on their knowledge of the nutritional needs of preschoolers. It was therefore recommended that;

1) Government and school management should organise workshop and sensitization programmes for parents of different occupation on knowledge of nutritional needs of preschoolers.

2) Federal ministry of education should collaborate with UNICEF and Food and Agriculture Organisation of the United Nations (FAO) to train parents from different occupation on knowledge of the cognitive readiness of preschoolers

3) Parents in both rural and urban areas should be provided with the same type of training by school management, religious bodies and women groups on knowledge of the nutritional needs of preschoolers.

\section{Acknowledgements}

The researchers acknowledged all the participants used for the conduct of this research. Parents of preschoolers and teachers in the study area are highly acknowledged for their esteemed cooperation during the conduct of the research.

\section{Competing Interests statement}

The authors declared that there are no competing or potential conflicts of interest.

\section{References}

Abolarin, E. E. (2014). The Influence of prenatal, home and environmental factors on learning outcomes of 
pre-primary school children.IOSR Journal of Research and Method in Education, 4(6), 84-92. https://doi.org/10.9790/7388-04638492

Adesanya, A. O. (2012). Family and marital issues. Ibadan: University of Ibadan Press.

Agbon, C. A. (2007). Nutritional status of rural preschool children in the university of agriculture Abeokuta extension villages (Unpublished $\mathrm{PhD}$ thesis, University of Nigeria, Nsukka).

Atkin, R. C. (2002). New diet revolution. New York: M. Evans and Company.

Awopetu, A., Awopetu, R., \& Obadiah, S. (2019). Fathers' knowledge and parenting practices as factors in promoting children's optimal development in early years in Nigeria. Journal of Early Childhood Association of Nigeria, 8(1), 223-240.

Barnett, W. S., \& Belfield, C. R. (2006).Early childhood development and social mobility. The Future of Children, 1(2), 73-98. https://doi.org/10.1353/foc.2006.0011

Chung-Park, M. S. (2012). Knowledge, opinions, and practices of infant sleep position among parents. Military Medicine, 177(2), 235-239. https://doi.org/10.7205/MILMED-D-11-00323

Dev, D. A., et al., (2017). Engaging parents to promote children's nutrition and health: Providers' barriers and strategies in head start and child care centers. American Journal of Health Promotion, 31(2), 153-162.https://doi.org/10.1177/0890117116685426

Ejieh, M. U. C. (2009). Pre-primary education in Nigeria: Policy implementation and problems. Elementary Education, 5(1), 58-64.

FAO/UNDP. (2001). Malnutrition. In: Encyclopedia of life sciences. London: Nature Publishing Group; The Macmillan Building.

Federal Republic of Nigeria (FRN). (2014). National policy on education. Abuja: NERDC Government Press.

Ijarotimi, O. S., \& Ijadunola, K. T. (2007). Nutritional status and intelligence quotient of primary schoolchildren in Akure community of Ondo State, Nigeria. Tanzania Health Research Bulletin, 9(2). https://doi.org/10.4314/thrb.v9i2.14307

International LabourOrganisation. (2008). International standard of classification of occupation: Structure, group definitions and correspondence tables. Retrieved from

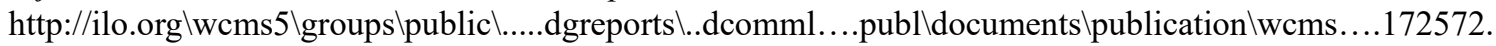
pdf

Kotler, P. (2003). Marketing Management (112th ed.). New York: Pearson Education Asia, pp 183-203.

Kumar, S. (2013). Role of educational qualification of consumers of need recognition: A study with reference to cars. Journal of Business Management, 27-31. https://doi.org/10.9790/487X-1252731

Lifecho, (2012). What is the role of a parent? The roles of being a parent.Retrieved from http://www.lifecho.com/what-is-the-role-of-a-parent-roles-of-being-a-parent/, accessed on 2nd March, 2019.

Melton, G. (2005). Treating children like people: A framework for research and advocacy. Journal of Clinical Child and Adolescent Psychology, 34(4), 646-657.https://doi.org/10.1207/s15374424jccp3404_7

Ngwoke, D. U., \& Eze, U. N. (2010). Developmental psychology and education: Theories, issues and trends. Enugu: Timex Enterprises.

Ngwu C. N., Ezeh, C. A., \& Iyiani, C. (2014). Knowledge of infant nutrition among mothers in Enugu state, south eastern, Nigeria: Implications for social work practice. International Journal of Academic Research in Progressive Education and Develop, 3(1). https://doi.org/10.6007/IJARPED/v3-i1/682

Ngwu, C. N. (2012). Knowledge of infant nutritional needs in Enugu state: Implications for child health in Nigeria (Unpublished PhD thesis, University of Nigeria, Nsukka).

Nworgu, B. G. (2015). Educational research basic issues and methodology.Nsukka: University Trust Press.

Ogomaka, P. M. C. (2005). Realistic quality assurance strategies in knowledge generation in Nigeria tertiary institutions. In: Ezeh, D. N. and Nkadi, O. (Eds.), Knowledge generation and dissemination: Issues and challenges in Nigerian universities (pp. 41-45). Enugu: Pearls and Gold.

Okolie, E. (2005). Diet Reform: The key to better health. Enugu: Niky Printing Press.

Okondugba, A. C. (2015). Demographic determinants of parents' perception of preschoolers' readiness to transit 
from home to school in Rivers state (Unpublished M.ED thesis, University of Nigeria Nsukka).

Schiffman, L. G., \& Leslie, L. K. (2004). Consumer behaviour (8th ed.). New Delhi: Prentice Hall of India Pvt. Ltd.

Sönmez, S., Kolaşınl, I. B., Topcan, Y., \& Paylaş, M. (2017). Investigation of the effectiveness of nutrition education applied to preschool children. European Journal of Social Science Education and Research, 4(4), 125-130. https://doi.org/10.26417/ejser.v10i2.p125-130

Srilakshmi, B. (2007). Dietetics. New Delhi: New Age International Publication.

Strauss, J., \& Thomas, D. (2008). Health over the life course. In: Schultz TP, Strauss J, (Eds.) Handbook of development economics (Vol. 4). Amsterdam: North Holland Press.

Ugochukwu, E. F., Onubogu, C. U., Edokwe, E. S., \& Okeke, K. N. (2014).Nutritional contents of lunch packs of primary school children in Nnewi, Nigeria. Annals of Medical and Health Sciences Research, 4(8), 108-114. https://doi.org/10.4103/2141-9248.138024

Unamma, R. (2003). Gender differences in the implementation of agricultural science curriculum: A conceptual overview. Journal of Curriculum Studies, 16(4), 210-218.

UNESCO. (2016).Creating sustainable futures for all; Global education monitoring report. Gender review, 20.

WHO, (2009). Preventing violence through the development of safe, stable, and nurturing relationships between children and their parents and caregivers. Geneva, Switzerland: World Health Organization.

Winter, L., Morawska, A., \& Sanders, M. (2012). The knowledge of effective parenting scale (KEPS): A tool for public health approaches to universal parenting programs. The Journal of Primary Prevention, 33(2-3), 85-97.

World Health Organization. (2009). Preventing violence through the development of safe, stable, and nurturing relationships between children and their parents and caregivers. Geneva, Switzerland: World Health Organization.

\section{Copyrights}

Copyright for this article is retained by the author(s), with first publication rights granted to the journal.

This is an open-access article distributed under the terms and conditions of the Creative Commons Attribution license (http://creativecommons.org/licenses/by/4.0/). 